\title{
Quantifying bacterial transfer from patients to staff during burns dressing and bed changes: Implications for infection control
}

\author{
Sarah E. Bache ${ }^{a, b, *}$, Michelle Maclean ${ }^{b}$, George Gettinby ${ }^{c}$, John G. Anderson ${ }^{b}$, \\ Scott J. MacGregor ${ }^{b}$, Ian Taggart ${ }^{a}$ \\ ${ }^{a}$ Burns Unit, Canniesburn Plastic Surgery Unit, Glasgow Royal Infirmary, Glasgow, United Kingdom \\ ${ }^{\mathrm{b}}$ The Robertson Trust Laboratory for Electronic Sterilisation Technologies (ROLEST), Department of Electronic and Electrical Engineering, \\ University of Strathclyde, Glasgow, United Kingdom \\ ${ }^{\mathrm{c}}$ Department of Mathematics and Statistics, University of Strathclyde, Glasgow, United Kingdom
}

\section{A R T I C L E I N F O}

Article history:

Accepted 4 December 2012

Keywords:

Infection control

Nosocomial infection

Healthcare workers

Contamination

Dressing change

Bed change

\begin{abstract}
A B S T R A C T
Routine nursing activities such as dressing/bed changes increase bacterial dispersal from burns patients, potentially contaminating healthcare workers (HCW) carrying out these tasks. HCW thus become vectors for transmission of nosocomial infection between patients. The suspected relationship between \%total body surface area (\%TBSA) of burn and levels of bacterial release has never been fully established.

Bacterial contamination of HCW was assessed by contact plate samples $(n=20)$ from initially sterile gowns worn by the HCW during burns patient dressing/bed changes. Analysis of 24 gowns was undertaken and examined for relationships between \%TBSA, time taken for activity, and contamination received by the HCW.

Relationships between size of burn and levels of HCW contamination, and time taken for the dressing/bed change and levels of HCW contamination were best described by exponential models. Burn size correlated more strongly $\left(R^{2}=0.82, p<0.001\right)$ than time taken $\left(R^{2}=0.52, p<0.001\right)$, with levels of contamination received by the HCW. Contamination doubled with every 6-9\% TBSA increase in burn size.

Burn size was used to create a model to predict bacterial contamination received by a HCW carrying out bed/dressing changes. This may help with the creation of burn-specific guidelines on protective clothing worn by HCW caring for burns patients.
\end{abstract}

(C) 2012 Elsevier Ltd and ISBI. All rights reserved.

\section{Introduction}

Advances in fluid resuscitation, organ support, and early excision and grafting have all improved survival rates following a severe burn [1]. However, this has also had the effect of shifting the cause of morbidity and mortality away from hypovolemia and towards sepsis. Sepsis is a primary risk factor of mortality following a burn [2,3]. It is now estimated that in patients with burns over $40 \%$ total body surface area (TBSA), $75 \%$ of all deaths are related to infection and/or inhalation injury [1]. Following a severe burn, physical, nonspecific and specific immune defences are all affected, leading to a state of immunosuppression. Coupled with large bacteria-

\footnotetext{
* Corresponding author.

E-mail address: sarahbache@doctors.org.uk (S.E. Bache). 0305-4179/\$36.00 (c) 2012 Elsevier Ltd and ISBI. All rights reserved. http://dx.doi.org/10.1016/j.burns.2012.12.005
} 
harbouring wounds, this renders burns patients both susceptible to infection and potent dispersers of bacteria [4]. The consequences of nosocomial propagation can be felt throughout the entire hospital, increasing costs and the risk of outbreaks of multidrug-resistant bacteria on the burns unit and beyond [5].

Transmission of infection between burns patients mainly occurs through airborne transmission or direct and indirect contact $[1,6]$. Routine nursing activity may create periods of increased bacterial dispersal into the air and onto surfaces and other individuals present in the vicinity. The present study examines the contamination of healthcare workers (HCW) resulting from burn wound dressing changes, which are often coupled with bed sheet changes.

Dressing changes on even small non-burn wounds create airborne dispersal of bacteria [7]. Bed sheet changes have also been shown to liberate bacteria into the air [8]. In the 1970s, attempts were made to link the size of a burn and the airborne dispersal of Staphylococcus aureus during a dressing change, which implied that the size of the burn was related to levels of bacteria found on settle plates over a period of days [9]. More recently, it was shown that $31 \%$ of dressing changes on methicillin resistant $\mathrm{S}$. aureus (MRSA) positive burns patients liberated the organism into the air [10].

HCW uniforms are a potential reservoir of infection [11-13], and their contamination can be directly attributed to patients $[14,15]$. Not only can bacteria be transferred from burns patients to uniforms during dressing changes, but also laboratory simulations have demonstrated that these bacteria can be transferred from the uniform to patients $[17,18]$. Despite this, there is little consensus for the appropriate protective attire to be worn by HCW carrying out dressing changes on burns patients. In a survey of US burns units, only $24 \%$ of units required full protective coverage on entering a patient's room and changing a dressing [19]. UK guidelines are similarly vague and not burns-specific [20-22]. Quantitative data on key issues may help in their development. In this context, the current study was set up to address the hypothesis that the level of contamination received by a HCW would be related to the size of the burn and the time taken for the dressing change.

\section{Materials and methods}

\subsection{Setting}

Quantification of HCW contamination was carried out during burn dressing changes. For patients with larger burns, the dressing change would usually also incorporate a bed sheet change while rolling the patient to apply bandages (hereafter termed 'dressing/bed change'). Data including age of burn, recent routine wound swab results, time taken for the dressing/bed change to take place and the \%TBSA burn were recorded for each patient. Patients were treated according to standard practice on our burns unit. We aim for early excision and split thickness skin autograft or coverage with a dermal substitute in all deep dermal and full thickness burns. Patients with superficial burns, or those deemed too sick for surgical intervention are managed conservatively with dressings and topical agents. Patients with burn wounds over 10 days old were excluded from the study.

\subsection{Sample standardisation}

To ensure that samples were taken from a standardised baseline, HCW were asked to don sterile, impermeable, disposable full-body gowns over their uniforms prior to performing dressing/bed changes. This was done to eliminate natural variations in bacterial contamination between different HCWs before the beginning of the dressing/bed change. It also provided a consistent sampling material, which was preferable to sampling from a variety of textures and surfaces including cotton and skin. Gowns were thus worn by the HCW only to facilitate the study design and sampling objectives. Usually, disposable plastic aprons would be worn over uniforms as routine bed/dressing changes are carried out. All HCW maintained standard hand hygiene by decontaminating hands and putting on fresh disposable gloves before entering the patient's room to carry out the nursing activity. Thereafter, with the exception of wearing disposable gowns rather than disposable plastic aprons over uniforms, the HCW carried out the dressing/bed change in the usual manner. Gloves were removed and hands washed following the dressing change and gown sampling, before leaving the room.

Samples were taken from the two most 'involved' HCW carrying out the dressing change, each of whom would usually stand either side of the bed and carry out undressing and redressing of wounds alongside one another. For smaller burns, one HCW often carried out the dressing change alone, and only one set of samples was obtained. Sampling during dressing/bed changes on any one patient was only carried out once.

\subsection{Sampling sites}

Following the dressing/bed change, and while the HCW was still wearing the disposable gown, and remained in the patient's room, the gown was sampled. To estimate the contamination that would be received during a dressing/bed change by a HCW who had not been wearing an apron, samples were taken from 20 sites across the front of the gown. The 20 'no apron' sites are illustrated in Fig. 1 . Of note, the sites are all across the front of the gown, as it was the aim of the study to collect samples from areas that were likely to become most contaminated during dressing/bed changes. In order to estimate the protection afforded had a disposable plastic apron been worn, a subset of 15 'with apron' sites were analysed separately. These excluded five sampling sites on the chest and abdomen that would normally be covered by a disposable apron. These are also demonstrated in Fig. 1.

\subsection{Bacteriological methods}

Samples were taken from the 20 sites using $25 \mathrm{~cm}^{2}$ Baird Parker Agar (BPA) contact plates that were pressed firmly against the sampling site for approximately $2 \mathrm{~s}$, by the same investigator (SEB). BPA allows for selective isolation of staphylococcal-type organisms, which are an accepted marker of bacteria originating from a human source [23]. A selective 


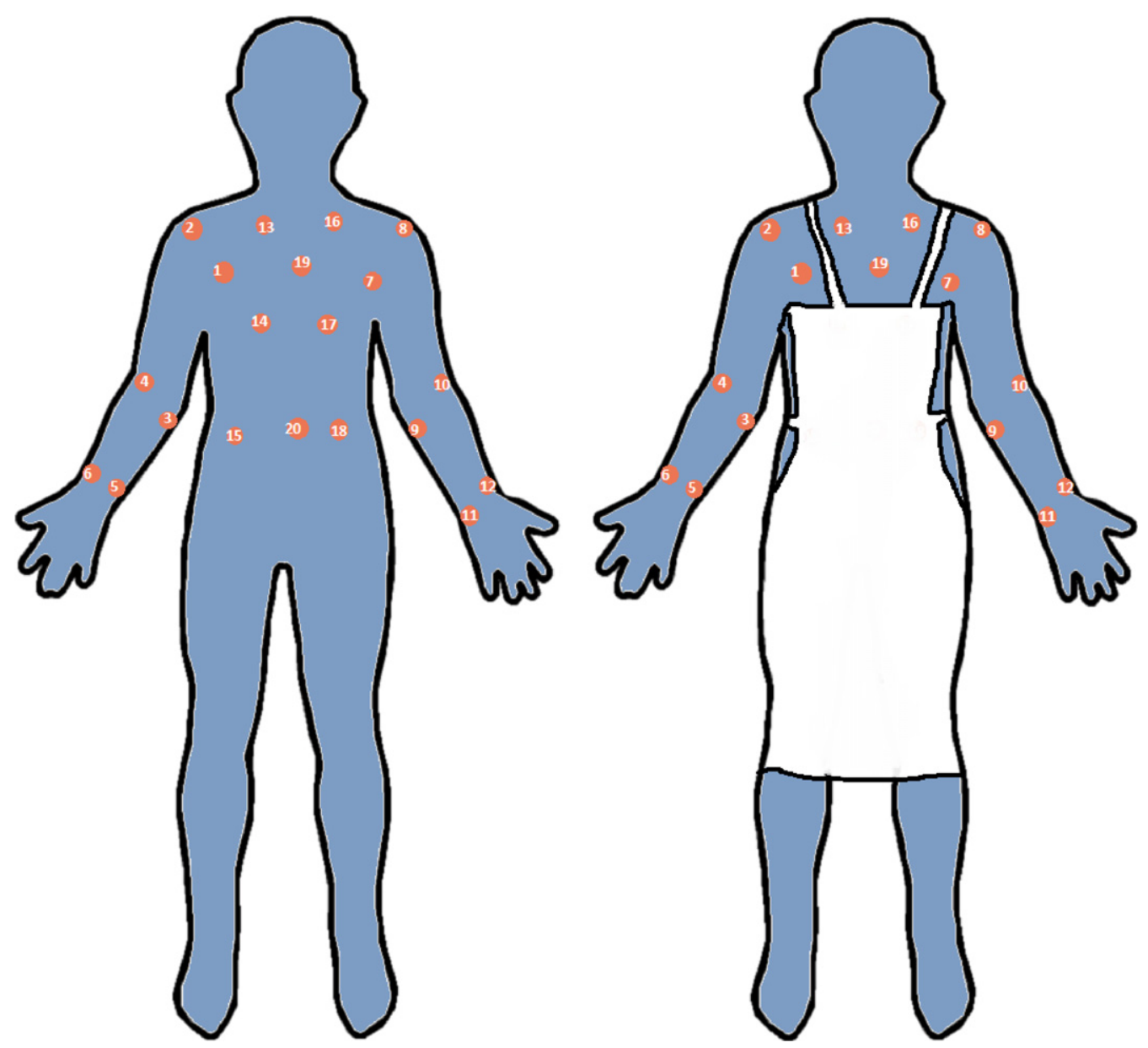

Fig. 1 - Diagram to demonstrate sampling sites on the front of HCW gowns. The image on the left shows the positions of all 20 sampling sites (termed 'no apron' sites). The image on the right highlights the 15 sampling sites left exposed if the HCW had been wearing an apron (termed 'with apron' sites). The two sets of samples were analysed separately.

agar was chosen over a non-selective agar as preliminary studies indicated that non-selective agar yielded too many bacterial colony-forming units (cfu) per agar plate to accurately enumerate. Contact agar plates allow direct sample collection from the contaminated gowns, and enable accurate reproduction of sampling due to the defined surface area of the agar plates. Sample plates were incubated at $37^{\circ} \mathrm{C}$ for $48 \mathrm{~h}$ before enumeration.

The time taken for the dressing/bed change to take place was measured from when the HCW entered the patient's room to commence the dressing/bed change (the point at which they would usually don a plastic apron). It finished at the point when the dressing and bed change (if that was also being carried out) was completed, when they would usually remove their apron and gloves prior to leaving the room. At this point the gown was sampled. Any further activities, including tidying the room, assisting with feeding, or brushing the patient's hair or teeth were not included in the time taken for dressing/bed change. The gown was sampled before these extra activities took place. This meant that the contamination measured was that received only during the dressing/bed change. It was not possible to separate the dressing and bed change components of the activity, as the bed sheet change was often integrated into the dressing change when the patient was rolled for application of bandages. We intended to mimic real-life situations as much as possible and did not want to inconvenience the patient or HCW, or prolong the activity by carrying out separate dressing changes and bed changes, during what can be a distressing and uncomfortable time.

\subsection{Statistical analysis}

In undertaking the study consideration was given to power and sample size required for the purposes of the regression and correlation analysis. It was estimated that measurements would be required on bacterial cfu and associated \%TBSA for a minimum of 10 patients in order to have in excess of $90 \%$ statistical power to detect a correlation of 0.9 with $95 \%$ confidence. A random sample size of between 10 and 15 patients was planned with replicate cfu measurements being observed on up to two HCW carrying out dressing/bed changes per patient.

HCW bacterial contamination was expressed as mean number of bacterial cfu per $25 \mathrm{~cm}^{2}$ agar plate, or mean $\mathrm{cfu} /$ plate. For each sampling session this was calculated for all 20 
'no apron' sites, and also for the 15 'with apron sites', excluding those 5 sites that would have been covered by a disposable plastic apron, had one been worn. Statistical analysis was carried out using NCSS Windows Version 7 software. Relationships were examined for between three variables: \%TBSA and HCW contamination; time taken for the dressing/bed change and HCW contamination; \%TBSA and time taken for the dressing/bed change. Separate analysis was carried out on all 20 'no apron' sites, and on the 15 'with apron' sampling sites. Mathematical modelling was used to identify equations which best described the three relationships. These were used to predict the contamination a HCW would receive during dressing/bed change of a burn patient by $\%$ TSBA. The coefficient of determination, $R^{2}$ was used to measure how well the model fitted to the observed data and $p<0.05$ was considered significant.

\section{Results}

\subsection{Patient demographics and wound information}

Samples were collected from the gowns of $24 \mathrm{HCW}$ carrying out dressing changes on 15 different patients, with a mean burn size of 19\%TBSA (range 1-51\%TBSA). Mean age of patient was 39 years (range 19-85 years). Samples were taken a mean of 6.4 days after the burn (range 2-10 days). Mean time taken for the dressing change was $45 \mathrm{~min}$ (range 10-90 min). The most common organism identified on routine wound swabs was S. aureus. Bacillus sp., coliforms, and Streptococcus sp. were also commonly isolated. Results are summarised in Table 1.

\subsection{Relationship between time taken for dressing/bed change and \%TBSA}

A significant relationship was demonstrated between the time taken for the dressing/bed change to take place and the size of the burn (\%TBSA). This was explained by a linear correlation (coefficient of determination, $R^{2}=0.76 ; p<0.001$ ). This is demonstrated in Fig. 2.

\subsection{Analysis of 20 'no apron' sites}

The variation in contamination received by a HCW during a dressing/bed change when 20 'no apron' sampling sites were analysed was examined in relation to \%TBSA of the burn and time taken for the dressing/bed change. Both relationships were explained by exponential models. These were as follows:

Relationship between HCW contamination and \%TBSA (coefficient of determination, $R^{2}=0.82 ; p<0.001$ ):

Mean cfu/plate $=8.59 \operatorname{Exp}^{0.080 \times \% \mathrm{TBSA}}$

Relationship between time taken in min for dressing/bed change and HCW contamination (coefficient of determination, $\left.R^{2}=0.52 ; p<0.002\right)$ :

Mean $\mathrm{cfu} /$ plate $=17.44 \mathrm{Exp}^{0.034 \times \text { time taken in min }}$

These curves are illustrated in Fig. 3. Both charts demonstrate an exponential relationship between the variable (\%TBSA or time taken for the dressing/bed change to take place) and the contamination received by the HCW. However, although they are both significant relationships, time taken correlates less strongly than \%TBSA as shown by the lower $R^{2}$. \%TBSA is a more accurate predictor of HCW contamination than time taken for the dressing/bed change to take place.

\subsection{Analysis of 15 'with apron' sites}

The variation in contamination received by a HCW during a dressing/bed change when 15 'with apron' sampling sites was examined in relation to \%TBSA of the burn and time taken for the dressing/bed change. Both relationships were explained by exponential models. These were as follows:

Relationship between HCW contamination and \%TBSA (coefficient of determination, $\mathrm{R}^{2}=0.86 ; p<0.001$ ):

Mean cfu/plate $=2.05 \operatorname{Exp}^{0.110 \times \% \text { TBSA }}$

Relationship between HCW contamination and time taken in min for dressing/bed change (coefficient of determination, $\left.R^{2}=0.44 ; p=0.007\right)$ :

Mean cfu/plate $=15.98 \mathrm{Exp}^{0.034 \times \text { time taken in min }}$

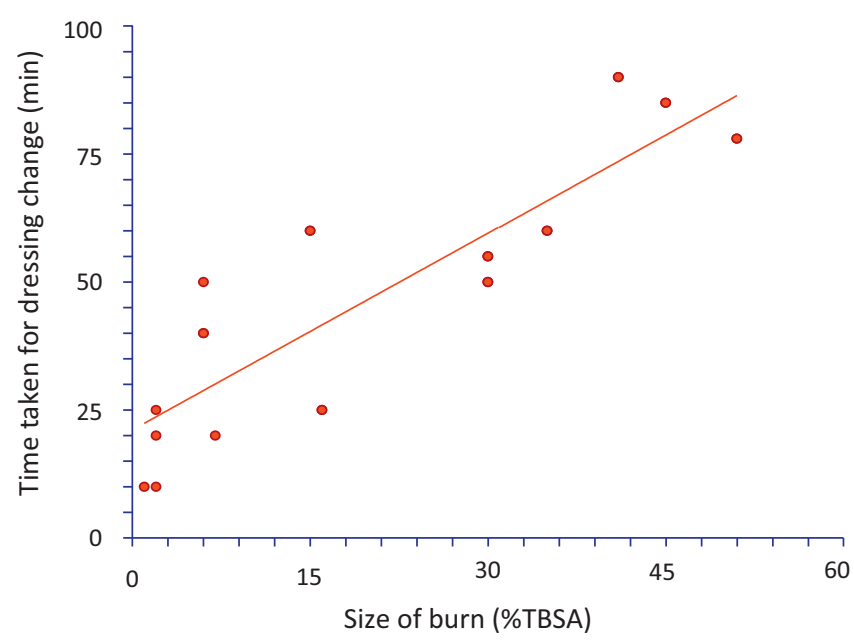

Fig. 2 - Chart demonstrating linear relationship between \%TBSA of the burn, and time taken in min to complete the dressing/bed change. 
Table 1 - Summary of all 24 studies of HCW carrying out dressing/bed changes on 15 patients. Details were taken of: size of burn as \% TBSA; site of burn (UL, upper limb; LL, lower limb; AT, anterior trunk; PT, posterior trunk; and HN, head and neck); depth of burn (SPT, superficial partial thickness; DPT, deep partial thickness; and FT, full thickness); age of burn in days; the \%TBSA that has been harvested as a split thickness skin graft; the \%TBSA that has been covered by autograft or dermal substitute; recent wound swabs; whether a dressing change and bed change took place; time taken for the dressing/bed change; and the mean cfu per plate for all 20 'no apron' sites, and the 15 'with apron' sites.

Study Patient Pt age \%TBSA Site of Depth of Age of \%TBSA \%TBSA Wound swab results Dressing Bed sheet Time Mean Mean

burn

burn burn donor site covered in

change change taken cfu/plate cfu/plate (days) harvested skin or (min) 20 sites 15 sites

\begin{tabular}{|c|c|c|c|c|c|c|c|c|c|c|c|c|c|c|}
\hline 1 & A & 19 & 1 & UL & DPT & 6 & 0 & 0 & Not taken & Yes & No & 10 & 23 & 18 \\
\hline 2 & B & 24 & 2 & $\mathrm{AT}$ & SPT & 6 & 0 & 0 & Not taken & Yes & No & 25 & 12 & 9 \\
\hline 3 & C & 26 & 2 & AT & SPT & 6 & 0 & 0 & Not taken & Yes & No & 10 & 14 & 5 \\
\hline 4 & D & 44 & 2 & UL & SPT & 10 & 0 & 0 & Not taken & Yes & No & 20 & 13 & 4 \\
\hline 5 & E & 34 & 6 & AT & DPT/FT & 8 & 6 & 6 & $\begin{array}{l}\text { Staphylococcus aureus, Bacil- } \\
\text { lus sp. }\end{array}$ & Yes & No & 40 & 40 & 27 \\
\hline 6 & E & 34 & 6 & AT & DPT/FT & 8 & 6 & 6 & S. aureus, Bacillus sp. & Yes & No & 40 & 13 & 5 \\
\hline 7 & $\mathrm{~F}$ & 33 & 6 & LL & DPT & 9 & 6 & 6 & $\begin{array}{l}\text { coliforms, S. aureus, Gp G } \\
\text { Streptococcus, Bacillus sp. }\end{array}$ & Yes & No & 50 & 1 & 1 \\
\hline 8 & G & 22 & 7 & UL & SPT & 8 & 0 & 0 & $\begin{array}{l}\text { coliforms, S. aureus, Gp A } \\
\text { Streptococcus, Bacillus sp. }\end{array}$ & Yes & No & 20 & 50 & 22 \\
\hline 9 & $\mathrm{H}$ & 45 & 15 & UL, AT, HN & FT & 6 & 9 & 15 & $\begin{array}{l}\text { S. aureus,, Bacillus sp., Clos- } \\
\text { tridium perfringens }\end{array}$ & Yes & Yes & 55 & 54 & 41 \\
\hline 10 & $\mathrm{H}$ & 45 & 15 & UL, AT, HN & FT & 6 & 9 & 15 & $\begin{array}{l}\text { S. aureus,, Bacillus sp., C. } \\
\text { perfringens }\end{array}$ & Yes & Yes & 55 & 50 & 21 \\
\hline 11 & I & 85 & 16 & AT & DPT/FT & 120 & 0 & 0 & S. aureus, Bacillus sp. & Yes & Yes & 25 & 101 & 90 \\
\hline 12 & I & 85 & 16 & AT & DPT/FT & 120 & 0 & 0 & S. aureus,, Bacillus sp. & Yes & Yes & 25 & 20 & 20 \\
\hline 13 & J & 39 & 30 & UL, LL, AT, PT & DPT/FT & 7 & 9 & 15 & $\begin{array}{l}\text { S. aureus, Streptococcus pneu- } \\
\text { monia }\end{array}$ & Yes & Yes & 50 & 108 & 118 \\
\hline 14 & J & 39 & 30 & UL, LL, AT, PT & DPT/FT & 7 & 9 & 15 & S. aureus, S. pneumoniae & Yes & Yes & 50 & 97 & 52 \\
\hline 15 & K & 46 & 30 & UL, LL, PT & DPT/FT & 6 & 0 & 0 & $\begin{array}{l}\text { S. aureus, Streptococcus sp., } \\
\text { Bacillus sp. }\end{array}$ & Yes & Yes & 55 & 28 & 7 \\
\hline 16 & $\mathrm{~K}$ & 46 & 30 & UL, LL, PT & DPT/FT & 6 & 0 & 0 & $\begin{array}{l}\text { S. aureus, Streptococcus sp., } \\
\text { Bacillus sp. }\end{array}$ & Yes & Yes & 55 & 25 & 26 \\
\hline 17 & $\mathrm{~L}$ & 55 & 35 & UL, LL, AT, & DPT/FT & 4 & 0 & 0 & $\begin{array}{l}\text { Methicillin resistant S. aur- } \\
\text { eus (MRSA) }\end{array}$ & Yes & Yes & 60 & 177 & 126 \\
\hline 18 & $\mathrm{~L}$ & 55 & 35 & UL, LL, AT, & DPT/FT & 4 & 0 & 0 & MRSA & Yes & Yes & 60 & 66 & 71 \\
\hline 19 & $\mathrm{M}$ & 29 & 41 & UL, PT, HN & FT & 8 & 18 & 18 & $\begin{array}{l}\text { coliforms, S. aureus, S. } \\
\text { pneumonii, bacillus sp. }\end{array}$ & Yes & Yes & 90 & 142 & 96 \\
\hline 20 & $\mathrm{M}$ & 29 & 41 & UL, PT, HN & FT & 8 & 18 & 18 & $\begin{array}{l}\text { coliforms, S. aureus, S. } \\
\text { pneumonii, bacillus sp. }\end{array}$ & Yes & Yes & 90 & 294 & 233 \\
\hline 21 & $\mathrm{~N}$ & 45 & 43 & UL, LL, AT, HN & FT & 2 & 1 & 18 & No growth & Yes & Yes & 85 & 287 & 259 \\
\hline 22 & $\mathrm{~N}$ & 45 & 43 & UL, LL, AT, HN & FT & 2 & 1 & 18 & No growth & Yes & Yes & 85 & 420 & 341 \\
\hline 23 & $\mathrm{O}$ & 40 & 51 & UL, AT, PT, HN & FT & 6 & 4 & 32 & Enterococcus cloacae & Yes & Yes & 78 & 662 & 569 \\
\hline 24 & $\mathrm{O}$ & 40 & 51 & UL, AT, PT, HN & FT & 6 & 4 & 32 & E. cloacae & Yes & Yes & 78 & 333 & 569 \\
\hline
\end{tabular}



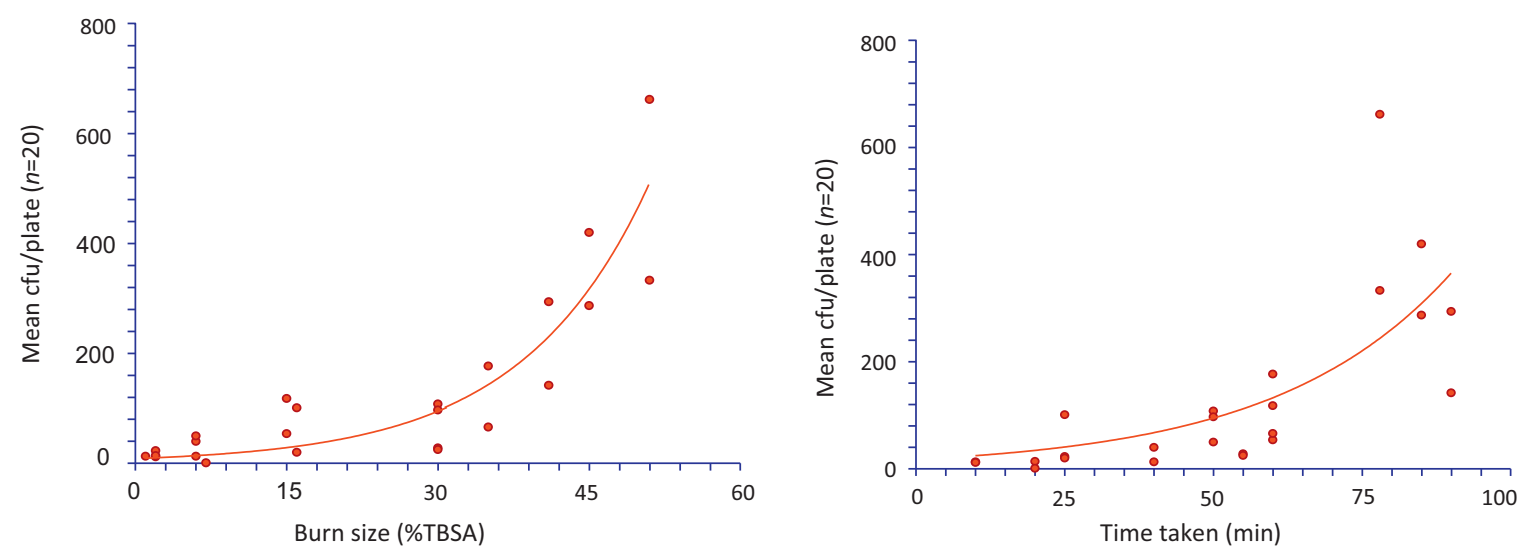

Fig. 3 - Charts demonstrating exponential relationships between \%TBSA and mean cfu per plate (left) and time taken in minutes for dressing change and mean cfu per plate (right) when all 20 'no apron' sampling sites on a HCW gown are analysed.
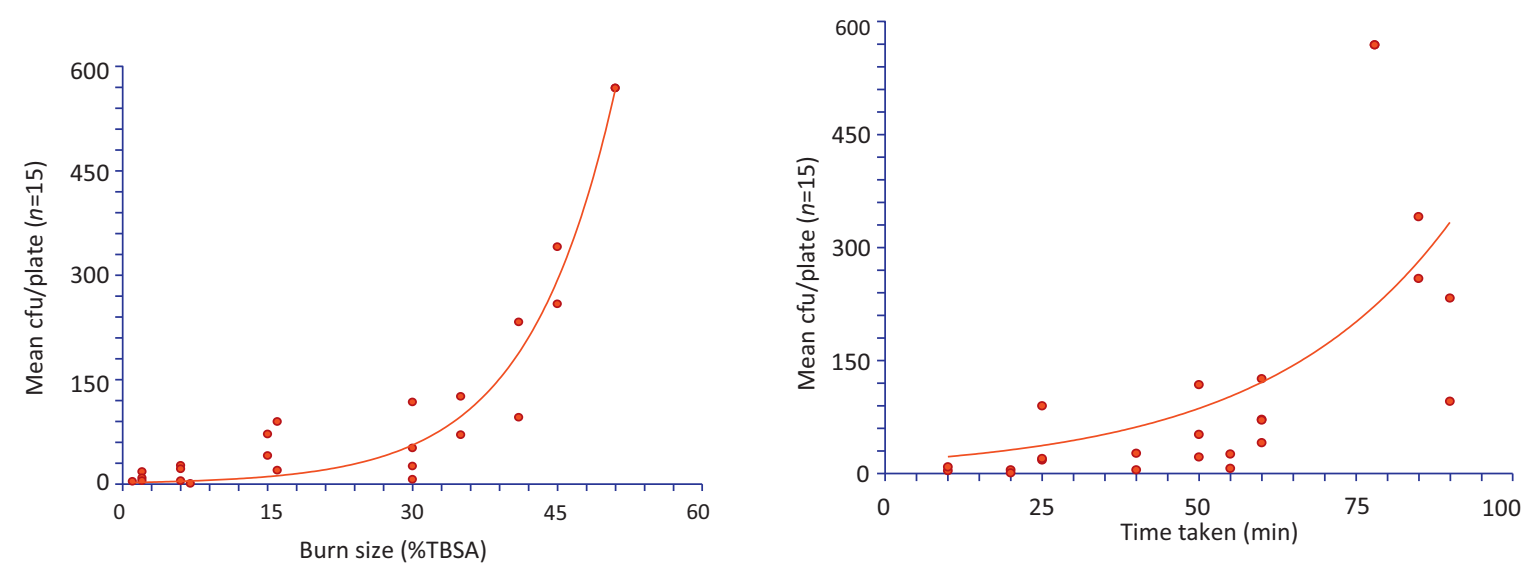

Fig. 4 - Chart demonstrating exponential relationships between \%TBSA and mean cfu per plate (left) and time taken in minutes for dressing change and mean cfu per plate (right) when 15 'with apron' sampling sites on a HCW gown are analysed.

These curves are illustrated in Fig. 4. Again, both charts demonstrate an exponential relationship between the variable (\%TBSA or time taken for the dressing/bed change to take place) and the contamination received by the HCW. However, although they are both significant relationships, time taken correlates less strongly than \%TBSA as shown by the lower $\mathrm{R}^{2}$. \%TBSA is a more accurate predictor of HCW contamination than time taken for the dressing/bed change to take place.

\subsection{Predicted contamination of HCW}

Using the above statistical models, the expected mean number of bacterial cfu per $25 \mathrm{~cm}^{2}$ plate from a HCW performing a burns dressing/bed change can be predicted. This was produced from data sets for all 20 'no apron' sites and the 15 'with apron' sites. These values are summarised in Table 2. It was found that for every 9\%TBSA increase in burn size, the mean number of cfu/plate doubled when all 20 sites were analysed. This was true for every $6 \%$ TBSA increase in burn size when 15 'with apron' sites were analysed.
Table 2 - Predicted mean contamination received by HCW performing a burn dressing/bed change. All 20 'no apron' sites, and the 15 'with apron' sites that would be left exposed if the HCW donned a plastic apron are analysed separately for comparison. Results are expressed as mean bacterial cfu per $25 \mathrm{~cm}^{2}$ agar plate.

\begin{tabular}{lcc} 
\%TBSA & $\begin{array}{c}\text { Predicted } \\
\text { mean cfu per } \\
\text { 25 } \mathrm{cm}^{2} \text { plate 20 'no } \\
\text { apron' sites }\end{array}$ & $\begin{array}{c}\text { Predicted } \\
\text { mean cfu per } \\
25 \mathrm{~cm}^{2} \text { plate 15 } \\
\text { with apron' sites }\end{array}$ \\
\hline 5 & 13 & 4 \\
10 & 19 & 6 \\
15 & 29 & 11 \\
20 & 43 & 18 \\
25 & 64 & 32 \\
30 & 95 & 56 \\
35 & 141 & 97 \\
40 & 211 & 168 \\
45 & 314 & 292 \\
50 & 469 & 507 \\
\hline
\end{tabular}




\section{Discussion}

The consequences of nosocomial infections from a burns patient cross-contaminating other patients are potentially devastating [1,24]. Prevention of cross-contamination is thus becoming an increasingly important area of burn care research. The potential for $\mathrm{HCW}$ to act as vectors of transmission between patients, and the increased bacterial dispersal during dressing and bed sheet changes on burns patients has long been known [6-9,11-18]. The current study highlights high levels of HCW contamination following a dressing/bed change and quantifies levels of bacterial contamination for the first time.

During a dressing/bed change the HCW can be expected to come into contact with the patient, their dressings and the surrounding environment, all of which are likely to be heavily contaminated on the burns unit. A HCW who has become contaminated by carrying out a dressing change will proceed to make contact with other patients or environmental surfaces, dispersing organisms, where they can survive for several weeks and form an environmental reservoir [25-27]. The environment may then contaminate another patient directly or indirectly via the hands or uniform of a HCW acting as a carrier for nosocomial infection $[28,4,29]$.

Guidelines on the use of protective clothing for HCW during burns dressing/bed changes are not burns-specific. Based on the results of this study, they may require to be revised with consideration of the amount of contamination received by HCW during performance of these routine nursing activities. The use of gloves and meticulous hand hygiene for all dressing changes is accepted practise and was not examined here $[15,30]$. Of note, WHO recommend a ' 5 moments for hand hygiene' approach whereby hands should be cleaned before and after all procedures and contact with patient surroundings [31]. It may be argued that the HCW in this study should have been encouraged to wash their hands several times during the activity, rather than just at the beginning and end. However as they were in constant contact with the environment, patient, and open wounds throughout the duration of the activity, dividing the dressing/bed change into distinct 'moments for hand hygiene' was difficult. One compromise that may be employed in the future is to encourage a pause for hand hygiene and change of gloves only, between removing dressings and applying fresh dressings. The compliance with these recommendations is however unlikely to affect the levels of bacteria found on the gowns, as they concern only hand hygiene.

Disposable full-body gowns were only worn for this study to enable sampling from a surface that was known to be sterile prior to the nursing activities. Standard practice on our unit is for plastic aprons to be worn for most dressing and bed changes, excluding those taking place in ICU or on known heavily contaminated patients. The results of this study have led to a review of our clinical practice, and revised guidelines on protective attire worn by HCW.

The mathematical models produced indicate that a HCW performing a dressing change on a patient with a 15\%TBSA burn could be expected to become contaminated with a mean of 29 bacterial $\mathrm{cfu} / 25 \mathrm{~cm}^{2}$ if they wore no protective clothing and 11 bacterial $\mathrm{cfu} / 25 \mathrm{~cm}^{2}$ if a plastic apron was worn, supposing absolute protection is afforded by the apron. For large burns, prediction of levels of contamination when a HCW wears or does not wear an apron highlights the limitation of relying only on the apron as a means of prevention of HCW contamination. For example, 50\% TBSA burn is estimated to produce $469 \mathrm{cfu} /$ plate when wearing 'no apron', compared to $507 \mathrm{cfu} /$ plate 'with apron'. The majority of samples were collected from the forearms, arms, shoulders and chest: areas that of skin and uniform which would not be protected or cleaned during hand washing and may come into contact with other patients or equipment. Before the study was initiated, HCW were encouraged to act exactly as they would were they wearing an apron. Whilst this was the agreed intention, it is nevertheless possible that they may have been less careful than usual knowing they were covered by a gown, or more careful as they were conscious they were part of a study. Regardless of this possible effect, the results highlight the need for a review of protective guidelines for HCW.

Burns between 2 and 10 days old were examined, although numerous factors such as the site of the burn, whether debridement had taken place, donor site size, comorbidities and bacteria isolated from the wound were unable to be controlled. Despite the inclusion criteria being fairly broad, \%TBSA was still shown to be an important predictor of HCW contamination. Future studies would be useful to monitor the change in HCW contamination as a burn progresses towards healing, or as the patient becomes colonised with increasingly resistant organisms. Furthermore, BPA was used throughout to monitor staphylococcaltype bacteria, but other selective media may be used in the future to identify other organisms that colonise burns wounds, such as Gram-negatives, which may show different transfer characteristics between patients and HCW. Were the studies to be repeated on a larger sample size, quantitative analysis of wound contamination may be attempted, although this would only be an estimate. However this would not be helpful in predicting contamination and thus guiding $\mathrm{HCW}$ on which protective attire to wear; results not being known until after the dressing/bed change had taken place.

Despite the relatively small sample size an excellent correlation of $82 \%$ was demonstrated, enabling the production of mathematical models. The largest burn studied was $51 \%$ TBSA so extrapolation to predict contamination from larger burns was not attempted. Although further studies may help to show the contamination produced by much bigger burns, at the upper limits of \%TBSA tested, many agar plates were very heavily contaminated, and much more contamination would probably render the number of bacterial cfu uncountable. Suffice to say contamination to at least the same extent would be expected for burns over $51 \%$ TBSA. It is important to note that all results are reported as cfu per $25 \mathrm{~cm}^{2}$ plate, and the total contamination across a whole gown would be many times this figure. What is not known is what constitutes a 'significant number' of bacteria. Further work would need to be carried out to determine the 
transfer rate from the HCW to another surface or patient. In the absence of this, an arbitrary figure may be assigned as a pre-determined cut off point above which full-body protection should be worn. The cost of full body protection must also be considered and weighed up against the perceived risk of transfer from a HCW.

It is logical to assume that in general a larger burn will take longer to dress, and indeed this was shown by a linear relationship between \%TBSA and total time taken (Fig. 2). Although time taken was related to the level of HCW contamination, it explained less of the variation than burn size, with a lower coefficient of determination, $R^{2}$. Furthermore, as the time taken for the dressing change will not be known until after the event, and may depend on HCW experience, \%TBSA was preferentially considered to predict HCW contamination. A rough guide is that for every 6-9\%TBSA increase in burn size, bacterial contamination doubles.

This study increases knowledge of the transfer of bacteria from burns patients to HCW. It highlights the need for guidelines on protective clothing worn by HCW to be developed, as burns patients have been shown to disperse high levels of bacteria onto HCW. For the first time, a quantitative analysis of bacterial contamination received by HCW performing burns dressing and bed changes have been performed. The risks of HCW contamination must be balanced against the cost of protective measures and resources available to burns units worldwide.

\section{Conflict of interest}

All authors declare no financial or personal associations that could inappropriately influence this work.

\section{Funding}

SEB would like to thank the Royal College of Surgeons of Edinburgh for the award of a small research grant for costs towards consumables for this research. No role was played by the funding source beyond this.

\section{Ethical approval}

Ethical approval was granted by the local REC for the study of levels of environmental bacterial contamination around burns patients, as part of a larger body of work. All samples were taken from disused gowns and no direct patient involvement was required to carry out this research. Verbal consent was obtained from the patient and HCW prior to the study.

\section{Acknowledgements}

SEB would like to thank the staff and patients on Ward 45 at GRI for their help with this study, and Mr. Stuart Watson for his support and advice.

\section{R E F E R E N C E S}

[1] Rafla $\mathrm{K}$, Tredget EE. Infection control in the burn unit. Burns 2011;37:5-15.

[2] Kasten KR, Makley AT, Kagan RJ. Update on the critical care management of severe burns. J Intensive Care Med 2011;26:223-36.

[3] Wang Y, Tang HT, Xia ZF, Zhu SH, Ma B, Wei W, et al. Factors affecting survival in adult patients with massive burns. Burns 2010;36:57-64.

[4] Weber J, McManus A. Infection control in burn patients. Burns 2004;30:A16-24.

[5] Talon D. The role of the hospital environment in the epidemiology of multi-resistant bacteria. J Hosp Infect 1999;43:13-7.

[6] Gould D. Isolation precautions to prevent the spread of contagious diseases. Nurs Stand 2009;23:47-55.

[7] Thom BT, White RG. The dispersal of organisms from minor septic lesions. J Clin Pathol 1962;15:559-62.

[8] Shiomori T, Miyamoto H, Makishima K, Yoshida M, Fujiyoshi T, Udaka T, et al. Evaluation of bedmaking-related airborne and surface methicillin-resistant Staphylococcus aureus contamination. J Hosp Infect 2002;50:30-5.

[9] Hambreus A. Dispersal and transfer of Staohylococcus aureus in an isolation ward for burned patients. J Hyg Camb 1973;71:787-97.

[10] Dansby W, Purdue G, Hunt J, Arnoldo B, Phillips D, Moody B, et al. Aerolization of methicillin-resistant Staphylococcus aureus during an epidemic in a burn intensive care unit. J Burn Care Res 2008;29:331-7.

[11] Babb JR, Davies JG, Ayliffe GAJ. Contamination of protective clothing and nurses' uniforms in an isolation ward. J Hosp Infect 1983;4:149-57.

[12] Perry C, Marshall R, Jones E. Bacterial contamination of uniforms. J Hosp Infect 2001;48:238-41.

[13] Callaghan I. Bacterial contamination of nurses' uniforms: a study. Nurs Stand 1998;13:37-42.

[14] Speers R, Shooter RA, Gaya H, Patel N. Contamination of nurses' uniforms with Staphylococcus aureus. Lancet 1969;2:233-5.

[15] Snyder GM, Thom KA, Furuno JP, Perencevich EN, Roghmann MC, Strauss SM, et al. Detection of methicillinresistant Staphylococcus aureus and vancomycin-resistant enterococci on the gowns and gloves of healthcare workers. Infect Control Hosp Epidemiol 2008;29:583-9.

[16] Morgan DJ, Liang SY, Smith CL, Johnson JK, Harris AD, Furuno JP, et al. Frequent multidrug-resistant Acinetobacter baumannii contamination of gloves, gowns, and hands of healthcare workers. Infect Control Hosp Epidemiol 2010;31:716-21.

[17] Hambreus A. Transfer of Staphylococcus aureus via nurses' uniforms. J Hyg Camb 1973;71:799.

[18] Hambreus A, Ransjo U. Attempts to control clothes-borne infection in a burn unit. J Hyg Camb 1977;79:193-203.

[19] Hodle AE, Richter KP, Thompson RM. Infection control practises in US burns units. J Burn Care Res 2006;27: 142-51.

[20] Pratt RJ. Epic 2: national evidence-based guidelines for preventing healthcare associated infections in NHS hospitals in England. J Hosp Infect 2007;65(S):51-64.

[21] Good practice in infection prevention and control guidelines for nursing staff. www.wales.nhs.uk/sites3/ Documents/739/RCN\%20infection\%20control.doc.pdf [accessed 03.11.11].

[22] NICE infection control guidelines: prevention of healthcare associated infection in primary and community care June 2003. http://www.nice.org.uk [accessed 03.11.11]. 
[23] Dancer SJ, White L, Robertson C. Monitoring environmental cleanliness on two surgical wards. Int J Environ Health Res 2008;18:357-64.

[24] Church D, Elsayed S, Reid O, Winston B, Lindsay R. Burn wound infections. Clin Microbiol Rev 2006;19:403-34.

[25] Boyce JM. Environmental contamination makes an important contribution to hospital infection. J Hosp Infect 2007;65(S2):50-4.

[26] Neeley AN. A survey of gram-negative bacteria survival on hospital fabrics and plastics. J Burn Care Rehabil 2000;21:523-7.

[27] Curtis L. Environmental control of methicillin resistant Staphylococcus aureus and other hospital acquired infections. J Burn Care Res 2008;29:1015.
[28] Arnow PM, Allyn PA, Nichols EM, Hill DL, Pezzlo M, Bartlett RH. Control of methicillin-resistant Staphylococcus aureus in a burn unit: role of nurse staffing. J Trauma 1982;22:954-9.

[29] Boyce JM, Potter-Bynoe G, Chenevert C, King T. Environmental contamination due to methicillin-resistant Staphylococcus aureus: possible infection control implications. Infect Control Hosp Epidemiol 1997;18:622-7.

[30] Bhalla A, Pultz NJ, Gries DM, Ray AJ, Eckstein EC, Aron DC, et al. Acquisition of nosocomial pathogens on hands after contact with environmental surfaces near hospitalized patients. Infect Control Hosp Epidemiol 2004;25:164-7.

[31] WHO guidelines on hand hygiene in healthcare. WHO Press; 2009, http://www.who.int/gpsc/5may/background/ 5moments/en/ [accessed 06.08.12]. 